\title{
Estimation of age specific incidence rates of childhood burns from a prevalence survey of burn scars
}

\author{
Samuel N Forjuoh, Penelope M Keyl, Marie Diener-West
}

\begin{abstract}
Objectives-This paper describes two methods of estimating the age specific incidence rates of childhood burns from a prevalence survey of burn scars.

Methods-A prevalence survey of burn scars was carried out in 1992 on 15742 Ghanaian children aged 5 years or less. Nine hundred and fifty five $(6.1 \%)$ of these children had scars from burn, and for 630 (66\%) of these children, additional information about the burn incident, including the child's age at the time of the burn, was obtained from the mother two to three months later. Thirty four per cent of mothers of children with burn scars were not interviewed due to absence, relocation, or inaccessibility. Age specific incidence rates of burns were estimated for eight age groups using two methods. In method $I$, the number of incident cases of burns for each age group were estimated from the burn scars by subtracting the estimated contribution of scars from burns that had occurred at earlier ages. In method II, the estimate was based on the mother's recall of the age of the child at the time of the burn.
\end{abstract}

Results-Slightly different results were obtained with the two methods, and problems were noted with both methods.

Conclusion-We recommend the use of these methods for estimating age specific incidence rates from retrospective population surveys for health conditions which result in long term residual markers.

(Injury Prevention 1997; 3: 207-210)

Keywords: childhood burn scars; Ghana; incidence rates; methods.

Population surveys are commonly used to study health problems, including injuries, in many parts of the world. Through such surveys, burns have been recognized as an important public health problem. ${ }^{1-4}$ Like other causes of injury and most common 'third world' diseases, such as malaria and schistosomiasis, burns are not random events and are, therefore, preventable. However, information on risk factors, including the age groups most at risk, is needed to formulate preventive strategies in any geographic areas.

While information on some risk factors are collected in population surveys, age specific incidence rates usually cannot be estimated from most surveys because they are cross sectional. The cost of conducting prospective studies for such purposes is prohibitive, particularly for most developing countries. However, for health problems that leave visible, distinctive, long term residual effects, it is possible to estimate age specific incidence rates from prevalence data.

When a child is burned, there are three possible outcomes. First, the burn may be serious enough to kill the child. Second, it may be so trivial as not to leave any visible scar. Third, it may result in a permanent scar. This scar is especially visible in dark skinned people, such as Ghanaians. Thus, a child who survives a non-trivial burn carries a permanent record of his or her burn experiences-the burn scar. This unique feature can be used to estimate age specific incidence rates of childhood burns, much in the same way as lameness, a distinctive sequela of poliomyelitis, has been used to estimate the incidence of residual paralytic poliomyelitis $^{5}$ or 'leopard skin', a unique feature of African onchocerciasis, to estimate the endemicity of this disease. ${ }^{6}$ An earlier version of this method of estimating the age specific incidence rates of childhood burns using burn scars has been previously reported. The results that were obtained are slightly different from those in this report, because $34 \%$ of the sample who could not be interviewed to ascertain details about the burn incident were excluded in the present analyses in order to compare the two methods using the same sample. Alternatively, age specific incidence rates of childhood burns can be estimated if the number of incident cases can be generated through maternal recall of the ages of children at the time of the burn.

In this report, we describe the application of these two methods of estimating the age specific incidence rates of childhood burns from a prevalence survey of burn scars. Our aim was to compare the results of the two methods in a Ghanaian population of children aged $0-5$ years who had scars from previous burns.

\section{Methods}

The data source for this study was a population based survey of childhood burns conducted in Ghana in 1992. Ghana is a developing country with a population of about 16.5 million and is \\ Correspondence to: \\ Center for Violence and \\ Injury Control, Alleghen \\ University of the Health \\ 4772, USA.
}


divided into 10 administrative regions. Ashanti Region, the study area, has a population of about 2.3 million. Details of the sampling method, survey design, response rates, and representativeness of the sample have been previously reported. ${ }^{89}$

In brief, 50 primary sampling units (PSUs) were randomly selected with equal probability from a total of 2177 PSUs in the region. Each PSU comprise one, two, or more adjoining villages or part of a town. Several households were then systematically selected from each PSU. All children residing in the chosen households ( $n=15742)$ were listed by trained, local health insepectors. The inspectors noted the age and gender of each child, and whether the child had ever been burned confirmed by checking for a visible scar. Mothers of 630 $(66 \%)$ of 955 children identified with burn scars ranging from 2 to $50 \%(\mathrm{SD}=3.4)$ of the body surface area were interviewed two to three months later by trained medical student interviewers. The remaining $34 \%$ were not interviewed due to absence, relocation, or inaccessibility arising from roads becoming impassable. Information was obtained from the mother on the child's age at the time of the burn. The study protocol was approved by the human subjects committee of the Johns Hopkins University and the Ministry of Health of Ghana, and data collection took place between July and December, 1992.

The prevalence rates of burn scars across eight age groups were computed. Age specific incidence rates of burns were then estimated for the eight age groups using two methods. In method I, incident cases of burns for each age group were estimated by subtracting the estimated contribution from younger age periods from the age specific scar prevalence. This method assumes a uniform distribution of children's ages within each age group, as well as a uniform distribution of the age at which the burn occurred within each age group. Age specific incidence rates were computed using the formulas:

$$
\begin{gathered}
I_{1}=\frac{p_{1}}{N_{1} \times \frac{1}{2}\left(\frac{t_{1}}{12}\right)} \\
I_{i}=\frac{p_{i}-\left[N_{i} \sum_{j=1}^{i-1}\left(I_{j} \times \frac{t_{j}}{12}\right)\right]}{N_{i} \times \frac{1}{2}\left(\frac{t_{i}}{12}\right)}
\end{gathered}
$$

Table 1 Distribution of number of burned children by each child's age at the time of the survey and mother's recalled age of each child at the time of the burn, Ashanti Region,

\begin{tabular}{|c|c|c|c|c|c|c|c|c|c|c|}
\hline \multirow{2}{*}{\multicolumn{2}{|c|}{$\begin{array}{l}\text { Age at time of } \\
\text { the survey }\end{array}$}} & \multicolumn{8}{|c|}{ Recalled age at the time of the burn in months $(j)$} & \multirow[b]{3}{*}{ Total } \\
\hline & & \multirow{2}{*}{$\frac{1}{0-5}$} & \multirow{2}{*}{$\frac{2}{6-11}$} & \multirow{2}{*}{$\frac{3}{12-17}$} & \multirow{2}{*}{$\frac{4}{18-23}$} & \multirow{2}{*}{$\frac{5}{24-35}$} & \multirow{2}{*}{$\frac{6}{36-47}$} & \multirow{2}{*}{$\frac{7}{48-59}$} & \multirow{2}{*}{$\frac{8}{60-71}$} & \\
\hline$i$ & Months & & & & & & & & & \\
\hline \multirow{9}{*}{$\begin{array}{l}1 \\
2 \\
3 \\
4 \\
5 \\
6 \\
7 \\
8\end{array}$} & $0-5$ & 1 & 0 & 0 & 0 & 0 & 0 & 0 & 0 & 1 \\
\hline & $6-11$ & 4 & 2 & 0 & 0 & 0 & 0 & 0 & 0 & 6 \\
\hline & $12-17$ & 0 & 11 & 5 & 0 & 0 & 0 & 0 & 0 & 16 \\
\hline & $18-23$ & 4 & 6 & 16 & 3 & 0 & 0 & 0 & 0 & 29 \\
\hline & $24-35$ & 1 & 7 & 22 & 46 & 37 & 0 & 0 & 0 & 113 \\
\hline & $36-47$ & 0 & 11 & 9 & 18 & 72 & 21 & 0 & 0 & 131 \\
\hline & $48-59$ & 4 & 8 & 11 & 11 & 31 & 70 & 18 & 0 & 153 \\
\hline & $60-71$ & 3 & 9 & 6 & 10 & 25 & 36 & 53 & 30 & 172 \\
\hline & Total & 17 & 54 & 69 & 88 & 165 & 127 & 71 & 30 & 621 \\
\hline
\end{tabular}
Ghana, fuly-December 1992 where $I_{i}$ is the number of burn cases per person year for age group $i ; p_{i}$ is the number of prevalent scars among children in age group $i$; $N_{i}$ is the number of children surveyed in age. group $i$; and $t_{i}$ is the length of the interval for age group $i$ in months. Additional assumptions? made using this method are that burns are not associated with a high mortality in this popula $\stackrel{5}{-}$ tion and that the age specific incidence of burns remained relatively constant during the six years before the survey.

In method II, which is based on maternaP recall, age specific incidence rates were comen puted using the estimated number of inciden $\overrightarrow{0}$ cases obtained by developing a matrix of theage of each child at the time of the survey and the mother's recollection of the age of the chilef at the time of the burn. In this matrix (see tablew 1) the rows $i$ represent the age group at the time of the survey, and the columns $j$ represen the recalled age group at the time of the burno Thus, the entries, $b_{i j}$, represent the observed number of children with scars surveyed in ages group $i$ whose mothers recalled their burnso taking place at age group $j$. The following formulas were then used to compute the age्ष्ठ specific incidence rates:

$$
\begin{gathered}
I_{1}=\frac{\sum_{j=1}^{n} b_{11}}{\left[\left(\frac{t_{1}}{12}\right)\left(\sum_{j=i+1}^{n} N_{j}+\frac{1}{2} N_{1}\right)\right]} \\
I_{i}=\frac{\sum_{j=i}^{n} b_{i j}}{\left[\left(\frac{t_{i}}{12}\right)\left(\sum_{j=i+1}^{n} N_{j}+\frac{1}{2} N_{i}\right)\right]}
\end{gathered}
$$

The second method uses information from the interview by medical students, which could not be carried out in several areas. Thus? analyses for the comparison of the two methods are restricted to the 10352 children in the 36 PSUs in which those interviews coulde be carried out.

\section{Results}

\section{PREVALENCE BY AGE GROUPS}

Of 630 children whose mothers completed the interviews, nine were missing data on the child's age at the time of burn. Table 29 presents the prevalence of burn scars for the remaining $621(99 \%)$ children by eight age

\begin{tabular}{|c|c|c|c|c|}
\hline $\begin{array}{l}\text { Age group } \\
\text { (i) }\end{array}$ & $\begin{array}{l}\text { Age at the } \\
\text { time of the } \\
\text { survey } \\
\text { (months) }\end{array}$ & $\begin{array}{l}\text { No of } \\
\text { children } \\
\text { surveyed }\end{array}$ & $\begin{array}{l}\text { No with } \\
\text { scars }\end{array}$ & $\begin{array}{c}\text { Prevalence } \\
\text { scars (\%) }\end{array}$ \\
\hline $\begin{array}{l}1 \\
2 \\
3 \\
4 \\
5 \\
6 \\
6 \\
7 \\
8\end{array}$ & $\begin{array}{c}0-5 \\
6-11 \\
12-17 \\
18-23 \\
24-35 \\
36-47 \\
48-59 \\
60-71\end{array}$ & $\begin{array}{r}852 \\
788 \\
720 \\
741 \\
1834 \\
1963 \\
1804 \\
1650\end{array}$ & $\begin{array}{r}1 \\
6 \\
16 \\
29 \\
113 \\
131 \\
153 \\
172\end{array}$ & $\begin{array}{r}0.12 \\
0.76 \\
2.22 \\
3.91 \\
6.16 \\
6.67 \\
8.48 \\
10.42\end{array}$ \\
\hline
\end{tabular}
groups. The prevalence increased from $0.1 \%$ for children $0-5$ months old to $10.4 \%$ for children 5 years of age. 
Table 3 Comparison of two methods of estimating the age specific incidence rates of childhood burns, Ashanti Region, Ghana, Fuly-December, 1992

\begin{tabular}{lccc}
\hline $\begin{array}{l}\text { Age } \\
\text { group } \\
\text { (i) }\end{array}$ & $\begin{array}{c}\text { Age at time of } \\
\text { the survey } \\
\text { (months) }\end{array}$ & $\begin{array}{c}\text { Method I: using } \\
\text { burn scars } \\
\text { (per 1000 person } \\
\text { years) }\end{array}$ & $\begin{array}{c}\text { Method II: using } \\
\text { maternal recall } \\
\text { (per 1000 person } \\
\text { years) }\end{array}$ \\
\hline 1 & $0-5$ & 4.69 & 3.41 \\
2 & $6-11$ & 21.07 & 11.77 \\
3 & $12-17$ & 37.36 & 16.4 \\
4 & $18-23$ & 30.29 & 22.91 \\
5 & $24-35$ & 59.62 & 25.69 \\
6 & $36-47$ & $\star$ & 28.02 \\
7 & $48-59$ & $\star$ & 26.81 \\
8 & $60-71$ & $\star$ & 34.25 \\
\hline
\end{tabular}

^Unable to compute.

AGE SPECIFIC INCIDENCE OF BURNS

The estimated age specific incidence of burns calculated using each method are shown in table 3. Using method I, children aged 24-35 months had the highest estimated incidence (59.6 per 1000 person years) followed by those aged 60-71 months, with infants $0-5$ months old having the lowest. The incidence of burns in children aged 24-35 months was about 13 times the rate for those aged $0-5$ months and twice the rate for those aged 18-23 months. No rates could be computed for children 36 months or older using method I due to the calculation of a negative number of incident cases, resulting from an overestimation of the number of scars in those age groups that were attributed to burns occurring at younger ages.

Using method II, the maternal recall matrix technique, children aged 60-71 months had the highest incidence (34.3 per 1000 person years), followed by those aged 36-47 months, with those $0-5$ months old again having the lowest. The estimated incidence of burns in children aged 60-71 months was about 10 times the rate for those aged $0-5$ months and one and half times the rate for those aged 1823 months. In general, rates tended to increase with age using this method.

\section{Discussion}

Two methods for estimating the age specific incidence rates of childhood burns from prevalence data using burn scars as a proxy and maternal recall are described in this paper. Method I was motivated by a technique used by LaForce et al to estimate the annual incidence of poliomyelitis from prevalence data on the premise that the clinical sequelae of paralytic poliomyelitis are so distinctive that, when observed, they can be attributed to poliomyelitis with a high degree of probability. ${ }^{5}$ Assuming a stable endemic situation, LaForce et al considered that paralysis due to poliomyelitis in the age group 5 years and above should reflect all the non-fatal cases with residual paralysis that occurred in this cohort between $0-4$ years. Surveys of residual paralysis in children 5-10 years old, adjusted with a factor to make up for fatal cases were, therefore, assumed to reflect the incidence of paralytic cases that had occurred one to 10 years earlier. ${ }^{5}$ Similarly, in this study we considered burn scars in children aged 0-5 years to reflect the incidence of burns that had occurred $0-5$ years before.

Different results were obtained using the two methods. However, the absence of a gold standard in this study by which to compare these two methods makes it difficult to decide which is the more reliable method. Based on the descriptive epidemiology of childhood burns in the study setting, ${ }^{9}$ coupled with the fact that no rates could be computed for the last three age groups using method I, the results obtained from method II may appear more plausible. In this study setting, the occurrence of burns in very young children is much lower than that in older children because the former are usually carried on the backs of their mothers most of the time. In addition, because older children 'play with fire' in the house yard, they may be more prone to burns. 9

There were some limitations with this investigation that must be considered in the interpretation of the results. First, computation of the age specific incidence rates of burns from the prevalence of burn scars is based on the assumption that burns to children occur uniformly in each age interval. This assumption may not be true. Second, the data, particularly the age of the child at the time of burn, is based on recall, and the data suggest a preference for reporting that the burn occurred at $12,24,36,48$, or 60 months, that is at 1,2 , 3,4 , and 5 years. This problem is similar to that reported by Lesthaeghe and Page. ${ }^{10}$ In addition, this recall bias may favor recent burns. Finally, although all burns share a single etiology-impact of thermal energy to the body - the mechanism of transmission of this energy may differ from case to case, and this method would not capture this level of detail.

Despite these limitations, we have demonstrated the use of two different methods for computing the age specific incidence rates of childhood burns from a prevalence survey. This information is essential to determining which particular age groups are at the greatest risk. The importance of identifying high risk groups is based on the premise that interventions are most effective and possibly most efficient when they target such groups. For this purpose, the precise age specific incidence may be less important than knowing which age groups have the highest rates, and this, in turn, assumes the interventions themselves are, in a sense, age specific.

We recommend the use of these methods in different populations to compare and refine the methods for estimating the age specific incidence rates of childhood burns from retrospective population based surveys. In addition, these methods are recommended for incidence studies of other health problems with long term residual effects. However, a caution is given about the issue of recall and digit preference, both of which should be taken into consideration in the design and analysis of future studies.

This study was funded by grants from the Rockefeller Foundation African Dissertation Internship Award, New York USA (\#RF 91037) and the International Development Research Council, Ottawa, Canada (\#92-0217). Dr Forjuoh is 
currently partly supported by grant number R49/CCR31028501A1 from the Centers for Disease Control and Prevention. The contents are, however, the sole responsibility of the authors and do not necessarily represent the official views of the funding bodies.

The authors wish to acknowledge the assistance from the Department of Community Health at the University of Science and Technology School of Medical Sciences, Kumasi, Ghana. This research formed part of Dr Forjuoh's doctoral dissertation research at the Johns Hopkins University. It was presented, in part, at the 123rd Annual Meeting of the American Public part, at the 123rd Annual Meeting of the American Public
Health Association, October-November 1995, San Diego, CA, USA.

1 Oluwasanmi JO. Burns in Western Nigeria. Br $\mathcal{F}$ Plast Surg 1969; 22: $216-23$.

2 Durrani KM. The epidemiology of burn injuries. Karachi: Mirror Press Ltd, 1974.

3 Cheng JCY, Leung KS, Lam ZC-L, Leung PC. An analysis of 1704 burn injuries in Hong Kong children. Burns 1990; 16: $182-4$.
4 Savage JP, Leitch IOU. Childhood burns: a sociological survey and inquiry into causation. Med f Aus 1972; i: $1337-42$.

5 LaForce FM, Lichnevski MS, Keja J, Henderson RH. Clinical survey techniques to estimate prevalence ant annual incidence of poliomyelitis in developing countries. Bull World Health Organ 1980; 58: 609-20. dungbola LD, Alabi TO, Oni GA, Asaolu SO, Ogunbanio BO, Parakoyi BD. 'Leopard skin' as a rapid diagnostic. index for estimating the endemicity of African onchoces ciasis. Int f Epidemiol 1987; 16: 590-4.

7 Forjuoh SN, Guyer B, Strobino DM, Keyl PM, Diener-West M, Smith GS. Risk factors for childhood burns: a case control study of Ghanaian children. $\mathcal{F}$ Epidemiol Commie nity Health 1995; 49: 189-93.

8 Forjuoh SN, Keyl PM, Diener-West M, Smith GS, Guyer Bग Prevalence and age-specific incidence of burns if Ghanaian children. F Trop Pediatr 1995; 41: $273-7$.

9 Forjuoh SN, Guyer B, Smith GS. Childhood burns ion Ghana: epidemiological characteristics and home-based. treatment. Burns 1995; 21: 24-8.

10 Lesthaeghe RJ, Page HJ. The post-partum non-susceptible period: development and application of model schedules. period: development and application
Popudies 1980; 34: 143-69.

\section{In-line skater injured}

A teen in-line skater was seriously injured after taking a midnight ride on a bus bumper. The 15 year old who was not wearing any protective gear, suffered multiple fractures when he crashed head-on with another bus travelling in the opposite direction ( $\mathrm{E}$ Collister, Gazette, 1 August 1996).

\section{A litany of fatal or near fatal injuries}

- 16 year old drowning in a hot tub has prompted consideration of laws requiring emergency shut-off switches

- Fall into family swimming pool results in severe brain injury to 3 year old

- 14 year old drowned after falling off a makeshift raft

- Child left in hot car prompts a bill in Massachusetts to make this a crime (it is a criminal offense to leave a dog in a hot car)

- A Rottweiler mauled an 11 year old so badly she required 100 stitches. Her mother blames the dog, not its owners

- Another child was mauled to death, also by a Rottweiler, after the chained dog grabbed the infant from a woman's arms

- Playing 'chicken' (sitting on the tracks) a teenager was killed by a commuter train travelling at $50 \mathrm{mph}$

- A 10 year old died after being run over by the family car. It appears he tried to move the car from the garage so he could play inside and was crushed under it as it rolled down the driveway

- Tot dies after fall in 5 gallon bucket filled with cleaning solution. 